\title{
Optimal Unemployment Insurance for Older Workers
}

JEAN-OLIVIER HAIRAULT, FRANÇOIS LANGOT

SEBASTIEN MENARD, THEPTHIDA SOPRASEUTH

\section{www.tepp.eu}

TEPP - Institute for Labor Studies and Public Policies TEPP - Travail, Emploi et Politiques Publiques - FR CNRS 3435 


\title{
Optimal Unemployment Insurance for Older Workers
}

\author{
Jean-Olivier Hairault * \\ Sébastien Ménard ${ }^{\ddagger}$
}

\author{
François Langot ${ }^{\dagger}$ \\ Thepthida Sopraseuth $\$$
}

October 2011

\begin{abstract}
At the end of working life, as well as reducing unemployment benefits, the unemployment-insurance agency could apply pension tax instead of wage tax. First, the pension tax provides greater incentives as the value of re-employment is tax-free. Second, the short job duration before retirement implies that the budgetary return and search incentives associated with the pension tax are considerable. By way of contrast, younger workers have greater search intensity and their future pension taxes are more remote and therefore more heavily-discounted: for them the wage tax is more efficient than is the pension tax. Finally, even in the special case where search intensity is zero close to retirement, perfect risk-sharing across unemployment and retirement is welfare-improving thanks to the pension tax.
\end{abstract}

Keywords: Unemployment insurance, Retirement, Recursive contracts, Moral Hazard. JEL Classification: C61, J64, J65.

*Paris School of Economics (PSE), University of Paris I Pantheon-Sorbonne and IZA. Email: joh@univ-paris1.fr. Financial support from a CEPREMAP grant (Paris) is gratefully acknowledged.

${ }^{\dagger}$ GAINS-TEPP, University of Maine, PSE and IZA. Email: flangot@univ-lemans.fr.

${ }^{\ddagger}$ GAINS-TEPP, University of Maine. Email: sebastien.menard@univ-lemans.fr.

${ }^{\S}$ GAINS-TEPP, University of Maine, PSE and CEPREMAP. Email: thepthida.sopraseuth@univlemans.fr.

ॠ We thank an anonymous referee and the Editor for their particularly helpful remarks and suggestions. We also thank participants at the SED, EALE, SCSE, SESAME and AFSE conferences and at the CEPREMAP workshop on "Labor-market Dynamics over the Life Cycle" for useful comments. We have benefited from fruitful discussions with P. Cahuc, S. Pallage, F. Portier, H. Sneessens and Y. Zenou. Any errors are our own. 


\section{Introduction}

In many European countries, unemployment-insurance requirements are less stringent for older workers (see OECD (2006) for more details on all of these programs). In some countries (Belgium, Finland, France, Germany and the United Kingdom), older people on unemployment benefits are exempt from the general eligibility requirement of having to look for work after a certain age; this was also previously the case in Austria and the Netherlands. In other countries (Ireland, Sweden), the job-search requirements for older unemployment benefit recipients are non-zero, but still less demanding than those for the younger unemployed. The "unemployment tunnel" leading to early exit from the labor market pertains as a result of the general exemption from job-search requirements for the older unemployed. This allows them to remain on unemployment benefits until they reach the official retirement age. In this sense, unemployment benefits are often considered as early retirement or pre-retirement schemes (Gruber and Wise (1998)).

This paper analyzes the economic rationale behind this policy. Since the seminal work of Shavell and Weiss (1979), it has been recognized that optimal unemployment benefits are such that the replacement ratio falls with unemployment duration. The provision of incentives to return to employment quickly comes from the assumption that the search intensity of the agent (the unemployed worker) is not be observed by the principal (the unemployment-insurance agency). Closer to retirement, we first show that the optimal insurance contract boils down to a simple constant-benefit scheme: the unemployment insurance agency chooses not to encourage job search by older workers. In this sense, the search exemption for older workers and early retirement schemes can be viewed as optimal. ${ }^{1}$

As such, this paper suggests the introduction of other instruments to affect the trade-off between insurance and incentives at the end of working life. Hopenhayn and Nicolini (1997) have already proposed an increasing wage tax after re-employment together with falling unemployment benefits. The principal uses this wage tax to provide a smoother consumption profile, while retaining some job-search incentives. However, faced with the short horizon of older workers once re-employed, we propose that the unemployment insurance agency take advantage of the retirement period to tax pensions in order to better reconcile insurance and incentives at the end of working life. Our analysis provides a basis for the integration of the unemployment and retirement schemes, allowing the agency to increase older workers' welfare. This is reminiscent of the unified insurance system proposed by Stiglitz and Yun $(2005) .^{2}$

The originality of our paper is the analysis of the characteristics of optimal unemployment

\footnotetext{
${ }^{1}$ Cremer et al. (2004) follow a different route to reach the same conclusion: early retirement is one ingredient of an optimally-designed redistributive policy in a world with asymmetric information.

${ }^{2}$ Stiglitz and Yun (2005) propose, in a very different framework, that unemployed workers should be able to borrow against future pensions. In the case of incomplete financial markets, this provides both insurance and effective incentives for all unemployed workers. There is nothing particular about older workers in their analysis.
} 
insurance for older workers. Young and old workers are intrinsically characterized by their different expected time horizons on the labor market. To the extent that there are search frictions on the labor market, the return to jobs is determined by their expected duration: a short horizon reduces search effort and thus the job-finding probability. ${ }^{3}$ The unemployment-insurance agency is then faced with intrinsically low search intensity by older workers, which will be zero for seniors who are close enough to retirement: intuitively, the unemployed who are one period away from retirement certainly will not search as this activity is costly but has zero return. Zero search may occur earlier, depending on the horizon prior to retirement necessary to recoup search costs. ${ }^{4}$

We here extend the framework of Hopenhayn and Nicolini (1997) by introducing a definitive exit from the labor market, i.e. retirement. More precisely, unemployed workers face a given probability of retiring. This probability is interpreted as a measure of their distance to retirement. Those with a higher probability of retiring correspond to older workers, while workers with a lower retirement probability are younger. We thus identify the optimal unemployment insurance for workers of different ages by looking at their different probabilities of retirement. It should be emphasized that agents do not age in our model, since the probability of exiting the labor market is independent of the time spent there. This allows us to compute easily the optimal contracts for any value of this probability. Taking into account agents' aging in addition to unemployment duration would add unnecessary complexity. Our simple theoretical framework captures, we believe, the essence of the retirement deadline effect on optimal unemployment benefits.

We show that in this framework there is a specific optimal design for the unemployment insurance of older workers. First, their closeness to retirement implies a sharply decreasing unemployment-benefit profile in order to motivate job search by the unemployed. Second, this policy is inefficient for unemployed who are close enough to retirement. A sharply decreasing profile would imply high unemployment benefits at the beginning of the unemployment spell in order to compensate for providing less insurance (less consumption smoothing). The cost of this profile would be too high for the unemployment-insurance agency, which then prefers to provide these soon-to-be retired unemployed with flat unemployment benefits, even though this means that they carry out no search. The agency then does not succeed in reconciling the insurance and incentive objectives, making search exemption optimal for these older workers when only unemployment benefits are used as a policy tool.

It is for this reason that imposing a tax on the future job, as in Hopenhayn and Nicolini (1997), could be of particular interest for older workers. This tax could both make the profile of unemployment benefits flatter while retaining job-search incentives via the rising

\footnotetext{
${ }^{3}$ This horizon effect has already received empirical support (Hairault et al. (2010)) and a theoretical foundation from job-search theory (Seater (1977) Ljungqvist and Sargent (2008) and Hairault et al. $(2010))$.

${ }^{4}$ This intrinsic feature of the oldest workers endogenously results as the corner solution of the optimal search problem, given that the search probability function we consider in this paper does not satisfy the Inada conditions.
} 
profile of the wage tax with unemployment duration. This then allows the principal to return some inactive unemployed older workers to work. However, faced with the short duration of re-employment, we show that a policy making the retirement pension depend on unemployment duration allows a better mix between incentives and insurance to be attained, at least for workers near to retirement.

First, the pension tax provides greater incentives as the value of re-employment is free of tax. Second, the short job duration pre-retirement renders the budgetary return and search incentives from the pension tax substantial. In contrast, the wage tax à la Hopenhayn and Nicolini (1997) is more efficient than the pension tax for younger workers with higher optimal search intensity and more heavily-discounted future pension taxes. Overall, the closer to retirement, the more efficient the pension tax is relative to the wage tax. Finally, even in the special case where search intensity is zero near retirement, perfect risk-sharing across unemployment and retirement is welfare-improving thanks to the pension tax: workers can borrow against their future pension to smooth consumption during unemployment. The effect of the pension tax works via two different channels: search incentives on the one hand and consumption smoothing on the other. When providing incentives becomes inefficient near retirement, some transfers from retirement to unemployment spells remain optimal in order to smooth consumption.

For a calibration based on workers aged over 50 in the French labor market, we propose a quantitative evaluation of the pension tax contract, especially relative to the wage tax contract. We show that the former allows unemployed workers to attain a smoother consumption profile, but also to search for a new job, whereas the proximity to retirement renders the other policies inefficient. This policy yields savings of about $40 \%$ of the existing unemployment insurance cost for unemployed workers 5 years prior to retirement. A tax on re-employment wages reduces the total cost of unemployed older workers by $34 \%$. This contrasts sharply with a decreasing unemployment insurance (UI) policy, which only lowers this cost by 3\%. Introducing a tax on pensions is then particularly useful in reconciling incentives and insurance for older workers near retirement when search is dramatically reduced by the short horizon on the labor market. This considerable reduction in total costs works mainly via search incentives rather than consumption smoothing. In this sense, our proposal is more along the lines of Hopenhayn and Nicolini (1997) than Stiglitz and Yun (2005).

Assuming that the unemployment agency can tax both wages after re-employment and pensions does not bring about any substantial additional efficiency as the two taxes are substitutes: the wage tax is no longer efficient with a very short horizon, whereas the pension tax is inefficient at longer horizons.

For the sake of simplicity, it should be emphasized that we omit financial asset accumulation, although it is known that the optimal contract is quite sensitive to this assumption. ${ }^{5}$ Our no saving assumption could be even less likely for older workers, who hold more finan-

\footnotetext{
${ }^{5}$ Shimer and Werning (2008) have recently shown that an insurance schedule that falls with unemployment duration performs worse than a flat rate in an economy where saving is allowed.
} 
cial assets than younger workers on average due to voluntary saving towards retirement. In that case, some borrowing against these future retirement funds might be possible. This reduces the interest of a pension tax close to retirement when only smoothing consumption matters, but also further from retirement, when search incentives still matter. In the latter case, dissaving throughout the unemployment spell acts as a substitute for the pension tax by penalizing consumption beyond the retirement age. However, in most countries, older workers have actually accumulated claims on Social Security. Contrary to financial assets, these assets are totally illiquid and not available before retirement. ${ }^{6}$ This is why our policy proposal may well perform better in countries relying on pay-as-you-go pension systems, which prevent workers from having access to their pension fund.

The paper is organized as follows. Section 2 describes the model and the two tax contracts. Section 3 proposes a quantitative evaluation, and Section 4 concludes.

\section{The model}

Our objective here is to determine the optimal schedule of UI benefits for older workers in a repeated moral-hazard environment. The first-best solution is not attainable, due to informational asymmetries: search effort is the agent's own private information, and the planner has no way of monitoring this effort. The second-best allocation is such that the principal (the UI agency) minimizes the expected discounted cost of the unemployment insurance, subject to two constraints: (i) to provide a certain expected lifetime utility level to the agent when she becomes unemployed; and (ii) to enforce the incentive-compatibility constraints implying that the agent makes her own optimal decisions for search effort given the optimal timing of UI benefits.

We assume that the agency has three possible instruments: unemployment benefits, wage taxes and pension taxes. These policy variables depend on the agent's unemployment duration. Our benchmark is the constant unemployment benefit policy. We then compare the optimal contract $\grave{a}$ la Hopenhayn and Nicolini (non-stationary UI and taxes on reemployment wages), denoted $P_{e}$, to a contract, denoted $P_{r}$, where there are pension taxes in addition to non-stationary UI.

The originality of our analysis is to introduce a finite horizon for workers. For simplicity, we present a model where workers are characterized by a given probability of retiring $\lambda_{w}$ which determines the expected horizon of the working life. Once retired, agents face a probability of dying $\lambda_{r}$. We choose this stochastic structure for computational reasons, as it reduces the dimension of the discrete state variables. With age as a deterministic and discrete state variable, the computational burden would have been dramatically higher.

\footnotetext{
${ }^{6}$ See Stiglitz and Yun (2005) for a similar statement.
} 


\subsection{The environment}

We now present the environment faced by the risk-neutral principal who provides the riskaverse agent with an optimal contract, given that the search effort of the latter cannot be observed by the former.

The behavior of the (unemployed) agent derives from both her preferences and the probability of retirement. If she finds a job in period $\tau$, then she is employed from $\tau+1$ until retirement, as jobs are permanent until retirement. ${ }^{7}$ An employed worker is assumed to receive a constant wage $w$, and a retiree a constant ${ }^{8}$ pension $p$. The agent's preferences are given by:

$$
E \sum_{\tau=0}^{\infty} \beta^{\tau}\left[u\left(c_{\tau}\right)-a_{\tau}\right]
$$

where $\beta<1$ denotes the intertemporal discount factor, $c_{\tau}$ consumption at time $\tau, a_{\tau}$ jobsearch intensity and $E$ the expectation operator. The instantaneous utility function $u(\cdot)$ is increasing, twice differentiable, and strictly concave with $u^{\prime}(0)=\infty$. We will assume that:

$$
u\left(c_{\tau}\right)=\frac{c_{\tau}^{1-\sigma}}{1-\sigma}
$$

where $\sigma>0$ is the coefficient of relative risk aversion. The probability of receiving a job offer depends on search intensity. This probability is given by an exponential distribution, as in Hopenhayn and Nicolini (1997):

$$
\pi(a)=1-\exp (-\psi a)
$$

with $\psi>0$. This hazard function is increasing, strictly concave, and twice differentiable. Note that this function does not satisfy the Inada conditions. More particularly, we have $\pi^{\prime}(0)=\psi<+\infty$. This means that the return to search may be dominated by search costs. This function is a parsimonious way of introducing fixed costs into job search. ${ }^{9}$ For a given set of parameters defining the environment and agent preferences, we will show that the probability of the zero-search corner solution rises with proximity to retirement. This function is then key in bringing out the particularity of older workers' job search. We denote the length of the previous unemployment spell by $t$. In the two contracts $\left(P_{e}\right.$ and $\left.P_{r}\right)$, unemployment benefits are $b(t)$ after $t$ periods of unemployment. Under

\footnotetext{
${ }^{7}$ Assuming that employment is permanent simplifies the analysis and is consistent with the literature. Hopenhayn and Nicolini (2009) relax this assumption.

${ }^{8}$ Pensions are not indexed on previous wages, as in real life, since we do not consider all the life-cycle history of workers. We then leave to one side the fact that retirement payments are already conditional on unemployment. However, this effect is not important in most countries as the indexation rules make the pension quasi-independent of unemployment spells. For instance, in France, the pension calculation is based on the best 25 years.

${ }^{9}$ In an equilibrium model of the labor market, the same result could be obtained when a fixed cost, corresponding for instance to training costs, is paid by the worker just after hiring (McMillan and Rothschild (1994)). From an empirical point of view, this assumption is supported by the observed importance of both the fixed costs of working and search costs in explaining participation decisions (see for instance Blundell et al. (1998)).
} 
the contract $P_{e}$, the unemployed worker pays taxes on wages of $\tau^{e}(t)$ when she becomes employed. As in Hopenhayn and Nicolini (1997), we assume that this tax depends on the length of the past unemployment spell $t$. Under the contract $P_{r}$, this tax payment is deferred until retirement, when the pension tax $\tau^{r}(t)$ is also assumed to depend on the length of the past unemployment spell $t$.

The value functions of the employed worker $\left(V^{e}\right)$, the retiree $\left(V^{r}\right)$ and the unemployed worker $\left(V^{u}\right)$ come from the solution to the following Bellman equations:

$$
\begin{gathered}
P_{e}:\left\{\begin{aligned}
& V^{e}\left(\tau^{e}(t)\right)=u\left(w-\tau^{e}(t)\right)+\beta\left[\left(1-\lambda_{w}\right)\left[V^{e}\left(\tau^{e}(t)\right)\right]+\lambda_{w} V^{r}\right] \\
& V^{r}=u(p)+\beta\left(1-\lambda_{r}\right) V^{r} \\
& V^{u}(t)=\max _{a(t)}\left\{\begin{array}{l}
u(b(t))-a(t)+\left(1-\lambda_{w}\right) \pi(a(t)) \beta V^{e}\left(\tau^{e}(t)\right) \\
+\left(1-\lambda_{w}\right)(1-\pi(a(t))) \beta V^{u}(t+1) \\
+\lambda_{w} \beta V^{r}
\end{array}\right\} \\
& P_{r}:\left\{\begin{aligned}
V^{e}\left(\tau^{r}(t)\right) & =u(w)+\beta\left[\left(1-\lambda_{w}\right) V^{e}\left(\tau^{r}(t)\right)+\lambda_{w} V^{r}\left(\tau^{r}(t)\right)\right] \\
V^{r}\left(\tau^{r}(t)\right) & =u\left(p-\tau^{r}(t)\right)+\beta\left(1-\lambda_{r}\right) V^{r}\left(\tau^{r}(t)\right)
\end{aligned}\right. \\
& V^{u}(t)=\max _{a(t)}\left\{\begin{array}{l}
u(b(t))-a(t)+\left(1-\lambda_{w}\right) \pi(a(t)) \beta V^{e}\left(\tau^{r}(t)\right) \\
+\left(1-\lambda_{w}\right)(1-\pi(a(t))) \beta V^{u}(t+1) \\
+\lambda_{w} \beta V^{r}\left(\tau^{r}(t)\right)
\end{array}\right.
\end{aligned}\right\}
\end{gathered}
$$

Under the contract $P_{e}$, taxes are collected during the re-employment spell. This makes the instantaneous value of employment a function of the wage tax. Under the contract $P_{r}$, taxes are paid once retired, whatever the job search outcome. On the other hand, the probability $\lambda_{w}$ determines the influence of either tax on the intertemporal values. The closer is retirement, i.e. the higher is $\lambda_{w}$, the smaller (greater) the influence of the wage (pension) tax on the value of employment. Optimal search effort, whatever the contract, is given by:

$$
1 \geq \beta \pi^{\prime}(a(t))\left(1-\lambda_{w}\right)\left[V^{e}\left(\tau^{x}(t)\right)-V^{u}(t+1)\right] \quad x=e, r
$$

with equality if $a(t)>0$. The right-hand side of equation (3) states that, for a given gap between the employment and unemployment values, the incentives to search fall with the probability of retirement $\left(\lambda_{w}\right)$. The return to job search then diminishes closer to retirement, whatever the policy. Moreover, as retirement becomes closer, the gap between the employment and unemployment value functions narrows, since they both depend on the same retirement value, except when a pension tax is allowed.

When the agent is going to retire tomorrow, she does not engage in any investment. This intrinsic feature of the oldest workers endogenously results as the corner solution of the optimal-search problem, given that the search probability does not satisfy the Inada conditions. In our stochastic aging framework, this occurs when $\lambda_{w} \rightarrow 1$. Overall, the probability of the corner solution $a=0$ rises with proximity to retirement. Following the same reasonsing, older workers intuitively search less than do younger workers. ${ }^{10}$ The optimal policy will exactly try to offset these effects by increasing job value close to retirement.

\footnotetext{
${ }^{10}$ Appendix A proposes formal proofs of these assertions in the simplified case without any active policies.
} 


\subsection{The optimal contract}

As in Hopenhayn and Nicolini (1997), the optimal unemployment-insurance contract consists of a sequence of unemployment benefits $B=\{b(1), b(2), \ldots, b(T)\}$ and taxes $\mathcal{T}=\left\{\tau^{x}(1), \tau^{x}(2), \ldots, \tau^{x}(T)\right\}$ : taxes are either on wages $(x=e)$ or on pensions $(x=r)$. Note that these taxes may be negative, and are then interpreted as subsidies. Given this contract, the agent maximizes intertemporal utility by choosing a sequence of search efforts. ${ }^{11}$

The principal's objective is to minimize total expenditure, under two constraints: (i) a given expected utility $V(1)$ for a newly-unemployed worker (the promise-keeping constraint), and (ii) an incentive-compatibility constraint. The program is thus:

$$
\begin{aligned}
C(V(t)) & =\min _{\mathcal{F}}\left\{\begin{array}{c}
b(t)+\beta\left(1-\lambda_{w}\right)(1-\pi(a(t))) C\left(V^{u}(t+1)\right) \\
+\left(1-\mathbb{I}_{x=r}\right)\left[\beta\left(1-\lambda_{w}\right) \pi(a(t)) G^{e}\left(\tau^{e}(t+1)\right)\right] \\
+\mathbb{I}_{x=r}\left[\begin{array}{c}
\beta\left(1-\lambda_{w}\right) \pi(a(t)) G^{e}\left(\tau^{r}(t+1)\right) \\
+\beta \lambda_{w} G^{r}\left(\tau^{r}(t+1)\right)
\end{array}\right]
\end{array}\right\} \\
\text { subject to } & \\
V(t) & \leq V^{u}(t) \\
\text { and } & \geq \beta \pi^{\prime}(a(t))\left(1-\lambda_{w}\right)\left[V^{e}(\tau(t))-V^{u}(t+1)\right]
\end{aligned}
$$

where $\mathcal{F} \equiv\left\{b(t), a(t), V^{u}(t+1), \tau^{x}(t)\right\}$, and $\mathbb{I}_{x=r}$ is an indicator function which equals 0 if the contract is $P_{e}$ and 1 if it is $P_{r}$. The functions $G^{e}\left(\tau^{e}(t+1)\right)$ and $G^{x}\left(\tau^{r}(t+1)\right)$ for $x=e, r$ are the discounted costs of taxes during the re-employment and retirement periods for the wage and pension tax respectively. They are defined as follows:

$$
\begin{aligned}
G^{e}\left(\tau^{e}(t+1)\right) & =\frac{-\tau^{e}(t)}{1-\beta\left(1-\lambda_{w}\right)} \\
G^{e}\left(\tau^{r}(t+1)\right) & =\frac{\beta \lambda_{w} \frac{-\tau^{r}(t)}{1-\beta\left(1-\lambda_{r}\right)}}{1-\beta\left(1-\lambda_{w}\right)} \\
G^{r}\left(\tau^{r}(t+1)\right) & =\frac{-\tau^{r}(t)}{1-\beta\left(1-\lambda_{r}\right)}
\end{aligned}
$$

Under the contract $P_{r}$, taxes are collected during the retirement period. This explains why the discounted cost of these taxes $G^{e}\left(\tau^{r}\right)$ during the re-employment period is relatively low for workers close to retirement: the higher is $\lambda_{w}$, the lower is $G^{e}\left(\tau^{r}\right)$. On the other hand, wage taxes are levied during the re-employment spell, which can be short for older workers: the higher is $\lambda_{w}$, the higher is $G^{e}\left(\tau^{e}\right)$.

The first-order conditions with respect to $b(t), V^{u}(t+1)$ and $V(t)$ for the principal's

\footnotetext{
${ }^{11}$ Unemployment benefits $b$ and search effort $a$ depend on the taxes and should thus be indexed by $e$ or $r$. For the sake of simplicity, we omit this index.
} 
problem are exactly the same, whatever the contract:

$$
\begin{aligned}
1 & =\mu u^{\prime}(b(t)) \\
C^{\prime}\left(V^{u}(t+1)\right) & =\mu-\nu \frac{\pi^{\prime}(a(t))}{1-\pi(a(t))} \\
C^{\prime}(V(t)) & =\mu
\end{aligned}
$$

On the other hand, the first-order conditions with respect to search intensity and the tax differ according to the tax policy considered $(x=e, r)$ :

$$
\begin{aligned}
\pi^{\prime}(a(t))\left[G^{e}\left(\tau^{x}(t+1)\right)-C\left(V^{u}(t+1)\right)\right] & =\nu \pi^{\prime \prime}(a(t))\left[V^{e}\left(\tau^{x}(t)\right)-V^{u}(t+1)\right] \\
\frac{1}{u^{\prime}\left(\mathbb{I}_{x=r} p+\left(1-\mathbb{I}_{x=r}\right) w-\tau^{x}(t)\right)} & =\mu+\nu \frac{\pi^{\prime}(a(t))}{\pi(a(t))} \mathcal{Z}^{x}
\end{aligned}
$$

with $\mathcal{Z}^{r}=\frac{\beta\left(1-\lambda_{w}\right) \pi(a(t))}{\beta\left(1-\lambda_{w}\right) \pi(a(t))+1-\left(1-\lambda_{w}\right) \beta}$ and $\mathcal{Z}^{e}=1$.

Together, equations (7), (8) and (9) yield unemployment benefits that fall with unemployment duration assuming an interior solution (see Appendix B). Moreover, using equations (10) and (11), it can be shown that the wage and pension taxes depend on unemployment duration (see Appendix B). The two contracts also exhibit some particular characteristics, that should be underlined.

First, as wages are higher than pensions, taxation during employment, when the marginal utility of income is lower, makes the transfer less costly to the agent (equation (11)). Ceteris paribus, this incites the principal to implement lower pension taxes than wage taxes.

Second, however, employment taxes have a perverse disincentive impact on the instantaneous value of re-employment, whereas pension taxes do not. Overall, it costs less to satisfy the incentive-compatibility constraint with the pension tax, which latter may then encourage search effort more than the wage tax, and lead some older unemployed workers to search for work. This explains why the pension tax may rise as the effect of the participation constraint in equation (11) falls $\left(\mathcal{Z}^{r}<\mathcal{Z}^{e}=1\right)$.

Third, proximity to retirement increases the relative efficiency of the pension tax: when re-employment duration is very short ( $\lambda_{w}$ high), a wage tax provides a small budgetary return for the agency (equations (4), (5) and (6)) and a small incentive effect for agents (equations (1) and (2)), leading to lower search intensity (condition (10)). Conversely, with younger workers the pension tax is less efficient, as both the tax revenue and incentives are heavily discounted. Overall, the higher is $\lambda_{w}$, the more efficient is the pension tax.

Finally, in the limiting case with no search effort, when retirement is imminent, the wage tax is no longer effective. This is significantly different from the pension tax, which is borne independently of the outcome of search. Even without search effort, the pension tax contract $P_{r}$ can smooth consumption across unemployment and retirement. In this case $(\nu=0)$, unemployment benefits and pension taxes are independent of unemployment 
duration: $C^{\prime}\left(V^{u}(t+1)\right)=C^{\prime}\left(V^{u}(t)\right) \Rightarrow V^{u}(t+1)=V^{u}(t)$ and $b(t)=b(t+1)=\widetilde{b}$, where $\widetilde{b}$ is greater than the constant unemployment benefit $b$ provided by the insurance agency in the benchmark economy without incentive contracts. ${ }^{12}$ From equations (7) and (11) for the $P_{r}$ contract, we have:

$$
\begin{gathered}
\frac{1}{u^{\prime}\left(p-\tau^{r}(t)\right)}=\frac{1}{u^{\prime}(\widetilde{b})} \\
\Rightarrow \tau^{r}(t)=p-\widetilde{b} \equiv \widetilde{\tau}^{r}, \forall t
\end{gathered}
$$

It is possible to smooth consumption across unemployment and retirement, even without unemployment-employment transitions. This consumption smoothing effect complements the incentive effect of the pension tax, and underlines the superiority of the pension tax when retirement is imminent.

\section{Integrating SS and UI programs}

In this section, we analyze the quantitative performance of integrating SS and UI programs, i.e. of considering a pension tax indexed on unemployment duration instead of a wage tax. Since there is no closed-form solution, we resort to numerical simulations ${ }^{13}$ based on a calibrated version of the model.

\subsection{Calibration}

The model is calibrated on a monthly basis and refers to the French economy with respect to the institutions and features of the labor market. Table 1 shows the different calibrated values according to their respective references or targets. We set the discount factor $\beta$ equal to 0.996. Following Hopenhayn and Nicolini (1997), the coefficient of relative risk aversion equals $\sigma=0.5$. The expected duration of retirement is set at 20 years. A retiree thus dies with a probability of $\lambda_{r}=(1 /(20 \times 12))$. The number $n$ of expected years prior to retirement is the key parameter and it is this that we will change in order to measure how unemployment insurance affects search behavior as individuals approach retirement $\left(\lambda_{w}=1 /(n \times 12)\right)$.

We normalize the wage $w$ to 100 , so that the unemployment benefit is the replacement rate. The latter $b$ is set to a constant value of 50 in the benchmark economy, which is the average replacement rate for individuals who are eligible for unemployment insurance. The pension level is calibrated to $p=70$, which is consistent with the replacement rate for French retirees in the late 1990s for an individual in the private sector with an earnings history corresponding to the average wage profile.

We choose to calibrate search efficiency $\psi$ using the unemployment duration of seniors. It is important to take into account the fact that this efficiency can fall during the life

\footnotetext{
${ }^{12}$ See Appendix D for a formal proof.

${ }^{13}$ Appendix E contains a short description of the calculations.
} 
Table 1: Calibrated values

\begin{tabular}{lll}
\hline \hline Parameter & \multicolumn{2}{c}{ Reference } \\
\hline Discount factor $\beta$ & 0.996 & Annual interest rate of 5\% \\
Relative risk aversion $\sigma$ & 0.5 & Hopenhayn and Nicolini (1997) \\
Retirement duration $\lambda_{r}$ & 0.0042 & Expected retirement duration: 20 years (COR (2001)) \\
Unemployment replacement rate $b($ in $\%)$ & 50 & French unemployment insurance agency \\
Retirement replacement rate $p($ in $\%)$ & 70 & Charpin (1999); French Retirement Council (COR (2001)) \\
& & \\
\hline Parameter & & Target \\
\hline Search efficiency $\psi$ & 0.0045 & Unemployment duration between 50 and 55: 11 months \\
\hline \hline
\end{tabular}

cycle due to lower labor demand for older workers: older workers may suffer from skill obsolescence via technological progress (see for instance Hellerstein, Newmark and Troske [1999]). This is why we consider in the following only workers with less than 10 years to retirement. Search efficiency $\psi$ is then set to 0.0045 so as to replicate the average unemployment spell for individuals aged 50-55 (between 10 and 5 years prior to retirement, at age 60 in France), who are not yet exempt from job-search requirements.

Given this calibration, the benchmark model with constant unemployment benefits implies that individuals who are 4 years and 5 months away from retirement exert zero search effort. This is very similar to the situation observed in France where the unemployed aged 55 or more choose to be exempted from job-search requirements when they are eligible to do so. ${ }^{14}$

\subsection{The intrinsic limit of the traditional optimal UI contract for older workers}

We present here some first results without tax instruments. This allows us to show the intrinsic limits of the traditional policy with only falling unemployment benefits, and hence the relative ability of the two tax policies to better circumvent reduced job search due to proximity to retirement.

As in Shavell and Weiss (1979), the unemployment insurance agency can choose to optimize using only the profile of unemployment benefits as a function of unemployment duration, without imposing taxes on either employment or the pension $\left(\tau^{e}(t)=\tau^{r}(t)=0\right.$, $\forall t$ ). Figure 1 shows the profile of unemployment benefits (panel (a)) and the job-finding rate (panel (b)) throughout the unemployment spell according to the distance to retirement, which is either 10 or 5 years. The shorter the labor-market horizon, the steeper the unemployment-benefit profile (Figure 1, panel (a)). Providing search incentives then requires a more severe punishment for those who do not find a job: after 15 months of unemployment, the replacement rate of older worker (the line with circles) is lower than

\footnotetext{
${ }^{14}$ All unemployed are eligible from age 57 onwards. Only those with sufficient years of contributions to Social Security are eligible at age 55 .
} 
that of younger worker (the line with crosses). The higher replacement rate at the beginning of the unemployment spell compensates for this steeper fall (Figure 1, panel (a)). As individuals approach retirement, they search less due to the distance effect (Figure 1, panel (b)). Zero search effort appears for individuals who are 4 years and 2 months away from retirement.

Figure 1: Downward sloping unemployment benefits
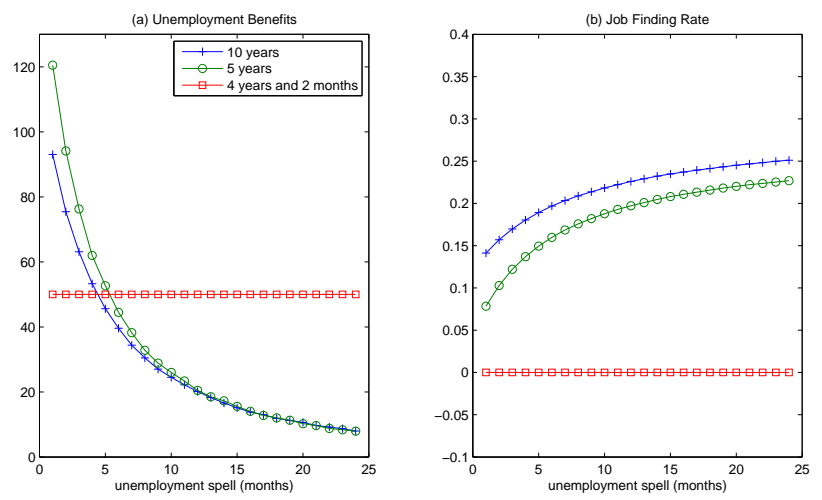

For workers who are a relatively long way away from retirement, reducing the replacement rate with unemployment duration is fairly efficient, as the cost is significantly reduced relative to the constant UI policy (the line with circles vs. the line with diamonds, Figure 4). But for workers who are closer to retirement (less than 4 years and 2 months away), this no longer reduces costs, as it does not manage to encourage job search by the older unemployed. These latter receive the benchmark constant UI benefits (Figure 1, panel (a)), and as a result there are no cost savings associated with this policy (Figure 4).

A short distance to retirement intrinsically limits the efficiency of decreasing unemployment benefits: a sharper decline in benefits would be required to motivate job search. The insurance agency would pay particularly high benefits today and promise particularly low benefits to individuals who are close to retirement. This scheme is eventually dominated by the constant benefits scheme at some proximity to retirement. The incentives consistent with promise-keeping are too costly and the unemployment-insurance agency has to renounce encouraging job search by these individuals: ${ }^{15}$ the agency can not reconcile the insurance and incentive objectives, making the recommendations by Shavell and Weiss (1979) irrelevant. In this sense, the search exemption for older workers and early retirement schemes in some European countries can be seen as optimal.

\subsection{A wage tax or a pension tax?}

An alternative view to this "giving-up" policy is to introduce another instrument, either a wage tax along the lines of Hopenhayn and Nicolini (1997), or a pension tax, as we

\footnotetext{
${ }^{15} \mathrm{~A}$ more formal intuition of this point is obtained from the first-order conditions at period 1 of the unemployment spell in Appendix C.
} 
suggest here.

Figure 2: Optimal insurance with a re-employment tax
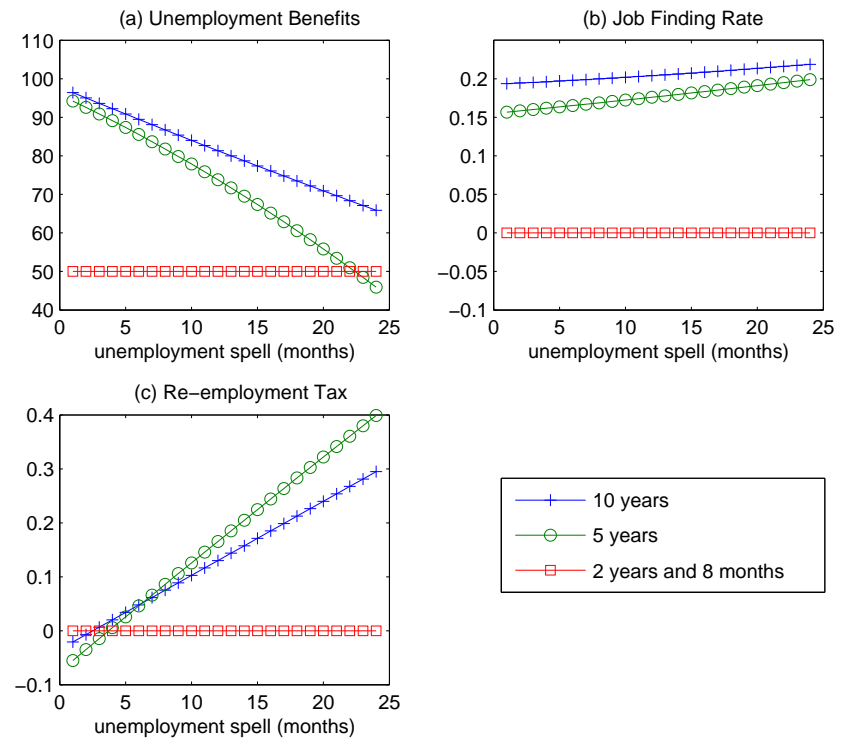

Greater incentives for job search by older workers. We first explore the design of the insurance contract with a wage tax after re-employment (Figure 2). Whatever the horizon, the unemployment benefits are now flatter than in the case without a wage tax (Figures 1 and 2, panel (a)), as the principal now has two policy instruments to induce the unemployed workers to search and smooth the consumption of the unemployed. By taxing future wages, individuals are encouraged to look for a job, while the slow decline in unemployment benefit ensures smoother consumption. This is particularly true for younger workers: Figure 2, panel (a) shows that at shorter horizons consumptionsmoothing is less effective.

Figure 3 illustrates the results for the optimal contract with a pension tax. As for the wage tax, the pension tax increases with unemployment duration (Figure 3, panel (c)): the unemployed who find a job quickly are even rewarded via a subsidy on the pension that will be paid over a 20 -year period on average. It should be emphasized that the carrot is more crucial than the stick in the case of the pension tax (Figures 2 and 3, panel (c)). This is intuitive as the agent suffers from lower income during retirement with respect to employment. As expected, the pension tax smoothes consumption more for workers who are 5 years from retirement than for those who are 10 years before (Figure 3, panel (a)), contrary to the wage tax.

On the other hand, whatever the horizon, search effort increases more under the pension tax (Figures 2 and 3, panel (b)), as the disincentive effect of the tax on the instantaneous value of employment is smaller. The pension tax then encourages more older workers to search for work. Only those who are less than 2 years from retirement are now charac- 
Figure 3: Optimal insurance with a pension tax
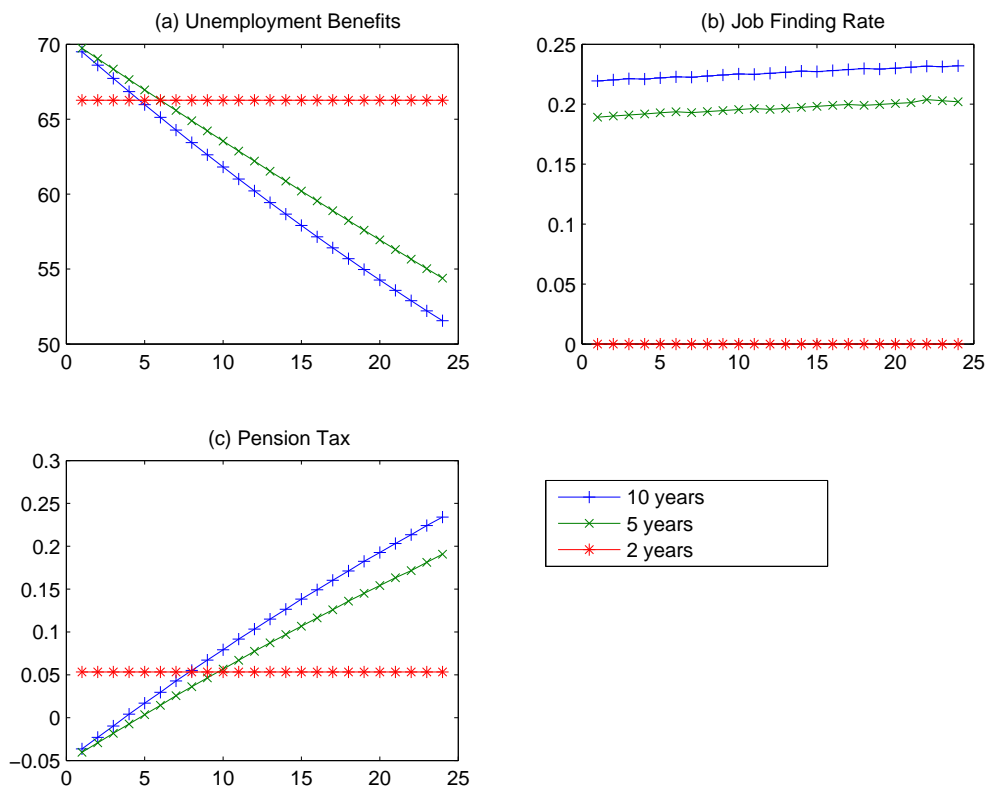

terized by constant optimal unemployment benefits (Figure 3, panel (a)) and zero-search effort (Figure 3, panel (b)), as compared to a figure of 2 years and 8 months for the wage tax (Figure 2, panels (a) and (b))).

Moreover, note that the pension tax is strictly positive for these inactive workers (Figure 3, panel (c)). By taxing retirement pensions, the planner increases consumption smoothing by transferring income from a period where individuals are better-off (retirement) to a period where they have a lower income (unemployment): the unemployment benefit is constant, but higher than that without a pension tax (67\% versus 50\%) (Figures 3 and 2, panel (a)).

Overall, for workers near to retirement, the pension tax seems to provide confirmation for the policy in Hopenhayn and Nicolini (1997) of taking the post-unemployment history into account.

Reducing the costs of the UI program. To confirm the above intuition, we need to compare the cost of each unemployment insurance policy according to the horizon of an unemployed worker up to retirement (Figure 4).

We should first emphasize that the cost evaluated at different horizons exhibits the same age profile, whatever the policy under consideration, and increases sharply when older workers with lower search intensities are considered. For each policy, the cost peaks at the distance to retirement (the distance threshold) at which search intensity is zero. For older unemployed workers, i.e. those who are closer to retirement than the distance threshold, search intensity naturally remains zero, but the cost is intuitively lower as the unemployment spell is mechanically shorter. On the other hand, the cost for workers who are further from retirement than the distance threshold is lower as these workers do search for a new job. 
The size of a given policy's cost reduction thus depends critically on its capacity to change this distance threshold: the closer to retirement is this threshold, the shorter the inactive unemployment spell and the lower the associated cost. The cost is particularly high when the unemployed do not search at long distances to retirement.

When unemployment benefits are flat, in the benchmark economy, older workers stop searching at 4 years and 5 months from retirement: this costs about 20 months of wages (Figure 4, the line with diamonds). Figure 4 shows that the differences between the policies considered are particularly large from this distance to retirement onwards. Imposing a tax on the future job along the lines of Hopenhayn and Nicolini (1997) or on the future pension as proposed in this paper is particularly efficient in the context of older workers. For instance, the introduction of taxes on wages and pensions reduces the cost of unemployment insurance at 4 years to retirement by more than $70 \%$ and $80 \%$ respectively (Figure 4, the lines with crosses and stars vs. the line with diamonds). We should note that any fall in unemployment benefits over the unemployment spell leads to a cost reduction at 4 years to retirement (Figure 4 , the line with circles vs. the line with diamonds). These results are notable as the costs of constant unemployment benefits are particularly high at 4 years to retirement in the benchmark economy, being about five times higher than at 10 years to retirement (Figure 4, the line with diamonds).

Figure 4: Cost of UI

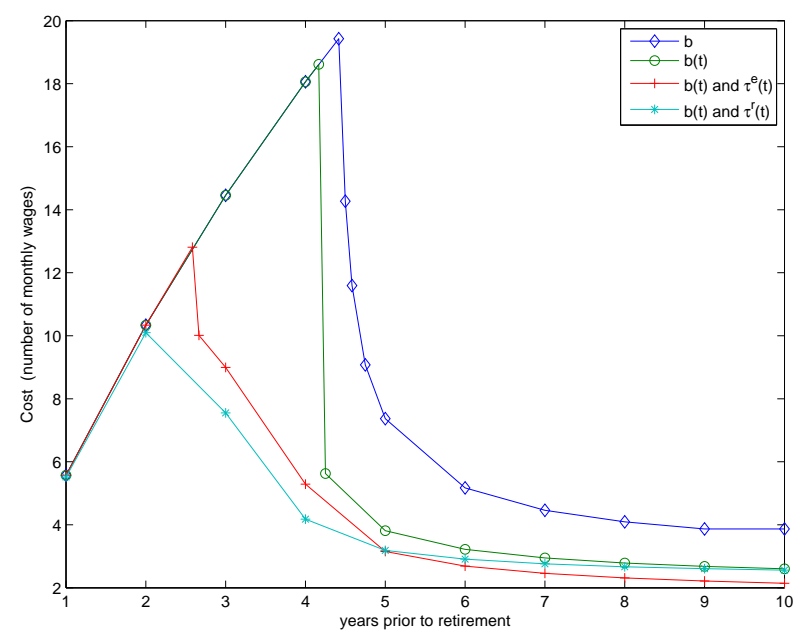

However, consistent with the analysis in Section 2.2, integrating UI and SS programs appears to be a more efficient strategy at older ages. The pension tax is more efficient than the wage tax for the unemployed who are sufficiently close to retirement, at less than 5 years to retirement (Figure 4, the line with crosses vs. the line with stars), especially between the two distance thresholds of 2 years vs. 2 years and 8 months. In contrast to the superiority of the pension tax near retirement, the wage tax is more efficient for younger unemployed workers (more than 5 years to retirement): at these longer horizons, as expected, the pension tax is less efficient, and the cost reduction from this tax converges to that provided by the policy without any taxes à $l a$ Shavell and Weiss (1979) (Figure 
4, the lines with circles and stars). However, it must be emphasized that the wage tax policy dominates when the insurance cost is relatively small, for workers who are more than 5 years from retirement. This illustrates the particular high return to integrating unemployment insurance and social security systems for the unemployed at the end of working life when search effort dramatically declines.

Even for individuals who are at the very end of their working life (less than 2 years from retirement), the pension tax allows unemployment-insurance costs to be reduced. At this horizon, none of the policies mentioned above yield positive search effort. But the policy integrating UI and Social Security does provide better consumption smoothing, which allows the principal to reduce the sum of revenues provided to the unemployed, net of taxes collected during retirement: at 2 years, the cost falls to 10.09 monthly wages, whereas it is 10.33 for the other policies (Figure 4). Almost $3 \%$ of the cost is then eliminated at the 2-year horizon due to this consumption smoothing effect of the pension tax. Even in the special case with no search, the perfect risk-sharing allocation is both available and efficient thanks to the pension tax which works as if workers could borrow against their future pension to smooth consumption during unemployment.

Overall, the effect of the pension tax is driven by the search incentives channel up to the threshold distance, and thereafter the consumption-smoothing channel up to retirement. When providing incentives become inefficient, it is optimal to make some transfers from retirement to unemployment, i.e. to tax the pension in order to mitigate imperfect financial markets. It seems that the search-incentive channel is much more important for cost reduction than this consumption smoothing: the cost reduction amounts to only $3 \%$ of the benchmark level at 2 years to retirement, but $80 \%$ of these costs at 4 years.

On the other hand, note that assuming that the unemployment agency can tax wages after re-employment as well as pensions ${ }^{16}$ does not significantly change our results. In particular, individuals who are 1 year and 11 months away from retirement are still characterized by constant optimal unemployment benefits. This two-tier policy does not bring any substantial additional power as the two taxes are rather substitutes for each other: the wage tax is no longer efficient at very short horizons, whereas the pension tax loses its efficiency at longer horizons.

\section{A global evaluation of a reform implementing the pension tax at 5 years to} retirement. Finally, we evaluate the cost reduction from a reform implementing the pension tax in France. We propose to introduce this policy for workers who are less than 5 years from retirement, set at age 60 in France. ${ }^{17}$ As can be seen in Figure 4, a policy with only decreasing unemployment benefits is fairly efficient in reducing the insurance cost for younger workers. This is no longer the case at less than 5 years to

\footnotetext{
${ }^{16}$ The principal would choose a contract defined by 3 vectors of instruments $B=\{(b(1), b(2), \ldots, b(T))\}$, $\mathcal{T}^{e}=\left\{\left(\tau^{e}(1), \tau^{e}(2), \ldots, \tau^{e}(T)\right)\right\}$ and $\mathcal{T}^{r}=\left\{\left(\tau^{r}(1), \tau^{r}(2), \ldots, \tau^{r}(T)\right)\right\}$. Taxes paid as an employee can be different from those paid as a retiree.

${ }^{17}$ The retirement age will be put back to 62 in December 2011, according to the 2010 reform.
} 
Table 2: Total cost reduction

\begin{tabular}{lccccc}
\hline \hline & \multicolumn{5}{c}{ Cost per worker in terms of monthly wage } \\
Age & $\begin{array}{l}\text { Flow into } \\
\text { unemployment }\end{array}$ & Constant UI & $\begin{array}{l}\text { Downward } \\
\text { sloping UI }\end{array}$ & $\begin{array}{l}\text { Tax on } \\
\text { wage }\end{array}$ & $\begin{array}{l}\text { Tax on } \\
\text { pension }\end{array}$ \\
55 & 13650 & 7.3672 & 3.8101 & 3.1506 & 3.1849 \\
56 & 11950 & 18.0587 & 18.0587 & 5.2891 & 4.1768 \\
57 & 22300 & 14.4578 & 14.4578 & 8.4924 & 7.5505 \\
58 & 32150 & 10.3359 & 10.3359 & 10.3359 & 10.0962 \\
59 & 13250 & 5.571 & 5.571 & 5.571 & 5.5152 \\
$\Delta$ Cost (\%) & & & -3 & -34 & -40 \\
& & & & & \\
\hline \hline
\end{tabular}

Note: Considering the flows into unemployment at different ages (second column), the cost per worker for each policy (columns from 3 to 6) is used to calculate the total cost of older workers' unemployment and so the reduction from each policy relative to the constant UI policy (last line).

retirement, making the two tax policies particularly useful. We take into account the number of unemployed older workers, which can magnify the reduction in the insurance cost provided to each unemployed worker. Table 2, Column 2, shows that the flows of new unemployed workers ${ }^{18}$ are particularly high at 57 and 58 in France, respectively 3 and 2 years prior to retirement. This could reinforce the strength of the pension tax, which is the only contract encouraging job search by the unemployed 2 years before retirement. Considering these flows, we use the cost per worker yield by our simulations for each policy (Table 2, Columns 3 to 6) to calculate the total cost of older workers' unemployment, and so the reduction yield of each policy with respect to the constant unemployment benefit case (Table 2, last row).

Overall, the total cost reduction from policies introducing taxes after the unemployment spell is much higher than that from a downward-sloping UI contract. The latter only cuts costs by $3 \%$, as opposed to $34 \%$ from the re-employment tax, and especially the figure of $40 \%$ from an additional tax on pensions.

The superiority of the pension tax comes mainly via the search-incentives channel, representing $98 \%$ of the total cost reduction. ${ }^{19}$ This reflects both the greater larger reduction in percentage terms allowed by the incentive channel and the much greater costs inflicted by the unemployed before the distance threshold when this channel is effective (Figure 4). This figure also reflects from the success of the pension tax in moving the inactivity zone closer to retirement.

\footnotetext{
${ }^{18}$ We consider the flows at different ages into the stock of unemployed workers. More precisely, we average these flows over the years 2006 and 2007. Data come from the French Department of Labor (Labarthe and Merlier (2008) and Labarthe and Merlier (2009)).

${ }^{19}$ This decomposition is calculated by considering the cost reduction before (incentives channel) and after (smoothing channel) the distance threshold, i.e. at age 58. We thank an anonymous referee for suggesting to quantify the relative importance of these two channels.
} 


\section{Conclusion}

Specific insurance programs for older workers in many European countries allowing them to retire early from the labor market are often viewed as responsible for the low employment rates at these ages. We show that the short distance to retirement implies certain particularities which can justify relinquishing active unemployment policies. Whereas the optimal strategy of the unemployment agency is to propose benefits which fall with unemployment duration for older workers who are several years from retirement, the optimal benefit contract becomes completely flat when retirement is imminent: this results from the inefficiency of such contracts when the horizons of both the agent and the principal are short. Some countries (Belgium, Finland, France, Germany and the United Kingdom) implement a general exemption from job-search requirements for older unemployed individuals. This paper provides an economic rationale for this looser job-search requirement for older workers, at least as long as conventional unemployment insurance contracts à la Shavell and Weiss (1979) are proposed.

On the other hand, we show that the inactivity of older workers could be reduced by introducing a pension tax. This is an appropriate tool to offset the effects of short expected job durations at the end of working life. Moreover, this is the only contract which is welfare-improving when going back to work is no longer incentive-compatible. This could also be the case when weak labor demand for some older workers makes their job search inefficient.

More generally, this paper proposes that the retirement age is a key institution that governs both search behavior and optimal unemployment benefits. In addition, age cannot be reduced to the biological age: the social age defined by the distance to retirement is the key dimension for both positive (Menzio et al. (2010)) and normative analysis (Chéron et al. (2011)). 


\section{References}

Blundell, R., J. Ham and C. Meghir (1998), 'Unemployment, discouraged workers and female labour supply', Research in Economics 52, 103-131.

Charpin, J. M. (1999), Rapport Au Premier Ministre : L'avenir de Nos Retraites, Documentation Française.

Chéron, A., J-O. Hairault and F. Langot (2011), 'Age-dependent employment protection', Economic Journal . Forthcoming.

COR (2001), Retraites : Renouveler Le Contrat Social Entre Les Générations, Conseil d'Orientation des Retraites.

Cremer, H., J.M. Lozachmeur and P. Pestieau (2004), 'Social security, retirement age and optimal income taxation', Journal of Public Economics 88, 2259-2281.

Gruber, J. and D. Wise (1998), 'Social security and retirement: An international comparison', American Economic Review 88(2), 158-163.

Hairault, J.-O., F. Langot and T. Sopraseuth (2010), 'Distance to retirement and older workers employment: The case for delaying the retirement age', Journal of the European Economic Association 8(5), 1034-1076.

Hopenhayn, H. and J.P. Nicolini (1997), 'Optimal unemployment insurance', Journal of Political Economy 105, 412-438.

Hopenhayn, H.A. and J. P. Nicolini (2009), 'Optimal unemployment insurance and employment history', Review of Economic Studies 76(3), 1049-1070.

Labarthe, J. and R. Merlier (2008), 'Le nombre de personnes dispensées de recherche d'emploi se stabilise en 2006', Premières Synthèses .

Labarthe, J. and R. Merlier (2009), 'La dispense de recherche d'emploi en 2007: des effectifs en baisse', Premières Synthèses .

Ljungqvist, L. and T. Sargent (2008), 'Two questions about european unemployment', Econometrica 76(1), 1-29.

McMillan, J. and M. Rothschild (1994), Search, in R.Aumann and S.Hart, eds, 'Handbook of Game Theory with Economic Applications', Elsevier Science B.V.

Menzio, G., I. Telyukova and L. Visschers (2010), Directed search over the life cycle, Technical report.

OECD (2006), Live Longer, Work Longer, Ageing and Employment Policies, OECD, Paris. 
Sargent, T. J. and L. Ljungqvist (2000), Recursive Macroeconomic Theory, MIT Press, Cambridge, Massachusetts.

Seater, J.J. (1977), 'A unified model of consumption, labor supply, and job search', Journal of Economic Theory 14, 349-372.

Shavell, S. and L. Weiss (1979), 'The optimal payment of unemployment benefits over time', Journal of Political Economy 87, 1347-1362.

Shimer, R. and I. Werning (2008), 'Liquidity and insurance for the unemployed', American Economic Review 98, 1922-1942.

Stiglitz, J.E. and J. Yun (2005), 'Integration of unemployment insurance with retirement insurance', Journal of Public Economics 89(11-12), 2037-2067. 


\section{A The case without active policy}

When unemployment benefits are constant, there are no state variables and the unemployment value $V^{u}$ is time-invariant, as is search intensity. The optimal behaviors are summarized by:

$$
\begin{aligned}
V^{e} & =\frac{u(w)+\lambda_{w} \beta V^{r}}{1-\beta\left(1-\lambda_{w}\right)} \\
V^{u} & =\frac{u(b)-a+\left(1-\lambda_{w}\right) \pi(a) \beta V^{e}+\lambda_{w} \beta V^{r}}{1-\beta\left(1-\lambda_{w}\right)(1-\pi(a))} \\
1 & \geq \pi^{\prime}(a) \beta\left(1-\lambda_{w}\right)\left(V^{e}-V^{u}\right)
\end{aligned}
$$

with equality if $a>0$.

Proposition 1. When $a>0$, the search intensity falls with $\lambda_{w}$.

Proof. Differentiating the equation system yields:

$$
\begin{aligned}
\frac{d V^{e}}{d \lambda_{w}} & =-\beta \frac{V^{e}-V^{r}}{1-\beta\left(1-\lambda_{w}\right)} \\
\frac{d V^{u}}{d \lambda_{w}} & =-\beta \frac{\left[\pi(a) V^{e}+(1-\pi(a)) V^{u}\right]-V^{r}}{1-\beta(1-\pi(a))\left(1-\lambda_{w}\right)}+\frac{\left(1-\lambda_{w}\right) \pi(a) \beta \frac{d V^{e}}{d \lambda_{w}}}{1-\beta(1-\pi(a))\left(1-\lambda_{w}\right)} \\
\frac{d a}{d \lambda_{w}} & =\frac{\pi^{\prime}(a)}{\pi^{\prime \prime}(a)\left(1-\lambda_{w}\right)\left(V^{e}-V^{u}\right)}\left[V^{e}-V^{u}-\left(1-\lambda_{w}\right)\left(\frac{d V^{e}}{d \lambda_{w}}-\frac{d V^{u}}{d \lambda_{w}}\right)\right]
\end{aligned}
$$

Because we always have $V^{e}>V^{r}>V^{u}$, it is possible to show that $V^{e}-V^{u}-(1-$ $\left.\lambda_{w}\right)\left(\frac{d V^{e}}{d \lambda_{w}}-\frac{d V^{u}}{d \lambda_{w}}\right)>0$, implying that $\frac{d a}{d \lambda_{w}}<0$, given that $\pi^{\prime \prime}(a)<0$.

The probability of the corner solution $a=0$ then rises with proximity to retirement.

Proposition 2. The probability that $a=0$ increases with $\lambda_{w}$. From a distance threshold onwards $\left(\lambda_{w}>\tilde{\lambda}_{w}\right)$, search effort is zero.

Proof. Assuming that $a=0$, for $b>0$, we have

$$
\left.\begin{array}{l}
V^{u}=\frac{u(b)+\lambda_{w} V^{r}}{1-\beta\left(1-\lambda_{w}\right)} \\
V^{e}=\frac{u(w)+\lambda_{w} V^{r}}{1-\beta\left(1-\lambda_{w}\right)}
\end{array}\right\} \Rightarrow V^{e}-V^{u}=\frac{u(w)-u(b)}{1-\beta\left(1-\lambda_{w}\right)}
$$

Using these value functions, the following inequality must be satisfied to be consistent with $a=0$ :

$$
1>\psi\left[\frac{\beta\left(1-\lambda_{w}\right)}{1-\beta\left(1-\lambda_{w}\right)}\right][u(w)-u(b)]
$$

For a given set of parameters $\{b, w, \beta, \psi\}$, this inequality holds more easily the higher $\lambda_{w}$ is. There exists a distance to retirement $\widetilde{\lambda}_{w}$ (the distance threshold hereafter) such that the condition (13) is just binding, i.e. is binding for $a=0$ :

$$
\psi\left[\frac{\beta\left(1-\widetilde{\lambda}_{w}\right)}{1-\beta\left(1-\widetilde{\lambda}_{w}\right)}\right][u(w)-u(b)]=1
$$

A value of $\lambda_{w}$ over $\widetilde{\lambda}_{w}$ necessarily leads to inequality (13). 


\section{B The dynamics of UI and pension taxes (contract $P_{r}$ )}

First, note that the optimal contract $P_{e}$ has exactly the same properties as in Hopenhayn and Nicolini (1997). On the other hand, considering the first-order conditions under contract $P_{r}$, it is possible to show that, assuming an interior solution, unemployment benefits fall with unemployment duration.

Equation (11) can be rewritten in the case of the pension tax contract as follows:

$$
\frac{1}{u^{\prime}\left(p-\tau^{r}(t)\right)}=\mu+\nu \frac{\pi^{\prime}(a(t)) \beta\left(1-\lambda_{w}\right)}{1-(1-\pi(a(t))) \beta\left(1-\lambda_{w}\right)}
$$

Defining $x(t)=1-(1-\pi(a(t))) \beta\left(1-\lambda_{w}\right)$, we then have:

$$
x(t) \frac{1}{u^{\prime}\left(p-\tau^{r}(t)\right)}=x(t) \mu+(1-x(t)) \nu \frac{\pi^{\prime}(a(t))}{1-\pi(a(t))}
$$

Using equation (8), implying that

$$
\nu \frac{\pi^{\prime}(a(t))}{1-\pi(a(t))}=-C^{\prime}\left(V^{u}(t+1)\right)+\mu
$$

we obtain:

$$
x(t) \frac{1}{u^{\prime}\left(p-\tau^{r}(t)\right)}=\mu-(1-x(t)) C^{\prime}\left(V^{u}(t+1)\right)
$$

Finally, using equation (9), we deduce that

$$
C^{\prime}\left(V^{u}(t)\right)=x(t) \frac{1}{u^{\prime}\left(p-\tau^{r}(t)\right)}+(1-x(t)) C^{\prime}\left(V^{u}(t+1)\right)
$$

Because

$\frac{1}{u^{\prime}\left(p-\tau^{r}(t)\right)}-C^{\prime}\left(V^{u}(t+1)\right)=\nu \frac{\pi^{\prime}(a(t))}{1-(1-\pi(a(t))) \beta\left(1-\lambda_{w}\right)} \Rightarrow \frac{1}{u^{\prime}\left(p-\tau^{r}(t)\right)}>C^{\prime}\left(V^{u}(t+1)\right)$

we deduce, using the fact that $C^{\prime}\left(V^{u}(t)\right)$ is an average between $C^{\prime}\left(V^{u}(t+1)\right)$ and $\frac{1}{u^{\prime}\left(p-\tau^{r}(t)\right)}$, that

$$
\frac{1}{u^{\prime}\left(p-\tau^{r}(t)\right)}>C^{\prime}\left(V^{u}(t)\right)>C^{\prime}\left(V^{u}(t+1)\right) \Rightarrow b(t)>b(t+1)
$$

We now turn to the analysis of pension taxes, which can be shown to also depend on unemployment duration. The forward iteration of equation (14) leads to:

$C^{\prime}\left(V^{u}(1)\right)=\sum_{j=0}^{T-1}\left(\prod_{i=0}^{j-1}(1-x(i+1))\right) x(j+1) \frac{1}{u^{\prime}\left(p-\tau^{r}(j+1)\right)}+\prod_{j=0}^{T}(1-x(j+1)) C^{\prime}\left(V^{u}(T+1)\right)$

Now assume by contradiction that pension taxes are constant. Then $a(t)$ would increase with $t$ because $V^{u}(t)$ is decreasing. We would then have:

$$
0<\prod_{j=0}^{T}(1-x(j+1))<(1-x(1))^{T}
$$


As $C^{\prime}\left(V^{u}(t)\right)$ is bounded, we can write:

$$
\lim _{T \rightarrow \infty} \prod_{j=0}^{T}(1-x(j+1)) C^{\prime}\left(V^{u}(T+1)\right)=0
$$

Moreover, given that $\lim _{T \rightarrow \infty} \sum_{j=0}^{T-1}\left(\prod_{i=0}^{j-1}(1-x(i+1))\right) x(j+1)=1$, we also have:

$$
\lim _{T \rightarrow \infty} \sum_{j=0}^{T-1}\left(\prod_{i=0}^{j-1}(1-x(i+1))\right) x(j+1) \frac{1}{u^{\prime}\left(p-\tau^{r}(1)\right)}=\frac{1}{u^{\prime}\left(p-\tau^{r}(1)\right)}
$$

implying that

$$
C^{\prime}\left(V^{u}(1)\right)=\frac{1}{u^{\prime}\left(p-\tau^{r}(1)\right)}
$$

which is not consistent with the envelope condition, which implies that

$$
\frac{1}{u^{\prime}\left(p-\tau^{r}(t)\right)}>C^{\prime}\left(V^{u}(t)\right)>C^{\prime}\left(V^{u}(t+1)\right)
$$

We then deduce that the pension tax $\tau^{r}(t)$ depends on the unemployment history.

\section{The limit of the contract with decreasing UI}

Assume that there are no taxes $\left(\tau^{e}(t)=\tau^{r}(t)=0\right)$. In this case, the optimal unemployment insurance contract $P_{u}$ is reduced to a sequence of unemployment benefits $B=\{b(1), b(2), \ldots, b(T)\}$. The first-order conditions of the problem are:

$$
\begin{aligned}
1 & =\mu u^{\prime}(b(t)) \\
C^{\prime}\left(V^{u}(t+1)\right) & =\mu-\nu \frac{\pi^{\prime}(a(t))}{1-\pi(a(t))} \\
C^{\prime}(V(t)) & =\mu \\
\frac{C^{u}\left(V^{u}(t+1)\right)}{V^{e}-V^{u}(t+1)} & =-\nu \frac{\pi^{\prime \prime}(a(t))}{\pi^{\prime}(a(t))}
\end{aligned}
$$

First, we define the natural upper bound of the value of unemployment $\sup \left(V^{u}(2)\right)$ above which the agent does not search. We have $a(1)>0$ if and only if:

$$
V^{u}(2)<V^{e}-\frac{1}{\psi \beta\left(1-\lambda_{w}\right)} \equiv \sup \left(V^{u}(2)\right)
$$

Consistent with Proposition 2 in Appendix A, the higher is $\lambda_{w}$ (older individuals), the less likely it is that this condition holds. Second, we focus on the relationship between the values of $b(1)$ and $V^{u}(2)$ resulting from the optimal trade-off between incentives and insurance. Consider the promise-keeping at period 1:

$$
V^{u}(1)=u(b(1))-a(1)+\beta\left\{\left(1-\lambda_{w}\right)\left[\pi(a(1)) V^{e}+(1-\pi(a(1))) V^{u}(2)\right]+\lambda_{r} V^{r}\right\}
$$


As $a(1)$ is a function of $V^{u}(2)$, the promise-keeping constraint defines an implicit relationship between $b(1)$ and $V^{u}(2)$ such that $b(1)=\Gamma\left(V^{u}(2), \lambda_{w}\right)$ with $\frac{\partial \Gamma}{\partial V^{u}(2)}<0$ and $\frac{\partial \Gamma}{\partial \lambda_{w}}>0$, assuming that the values for $V^{u}(t), \forall t \geq 3$, are given.

Moreover, assuming an interior solution, we have:

$$
\frac{1}{u^{\prime}\left(\mathcal{B}\left(V^{u}(2)\right)\right)}=\frac{1}{u^{\prime}(b(1))}-\frac{C\left(V^{u}(2)\right)}{V^{e}-V^{u}(2)}
$$

where $b(2) \equiv \mathcal{B}\left(V^{u}(2)\right)$ is obtained using the definition of the value function. Note that $\mathcal{B}^{\prime}\left(V^{u}(2)\right)>0$. This equation allows us to define another relationship between $b(1)$ and $V^{u}(2)$ such that $b(1)=\Upsilon\left(V^{u}(2)\right)$ with $\frac{\partial \Upsilon}{\partial V^{u}(2)}>0$ and $\frac{\partial \Upsilon}{\partial \lambda_{w}}=0$, if we also assume that the values for $V^{u}(t), \forall t \geq 3$, are given.

Overall, equations (15) and (16) determine the values of $b(1)$ and $V^{u}(2)$, which optimize the trade-off between incentives and insurance. Is this solution compatible with a binding incentive-compatibility constraint, i.e. $V^{u}(2)<\sup \left(V^{u}(2)\right)$ ?

Figure 5: Trade-off between insurance and incentives

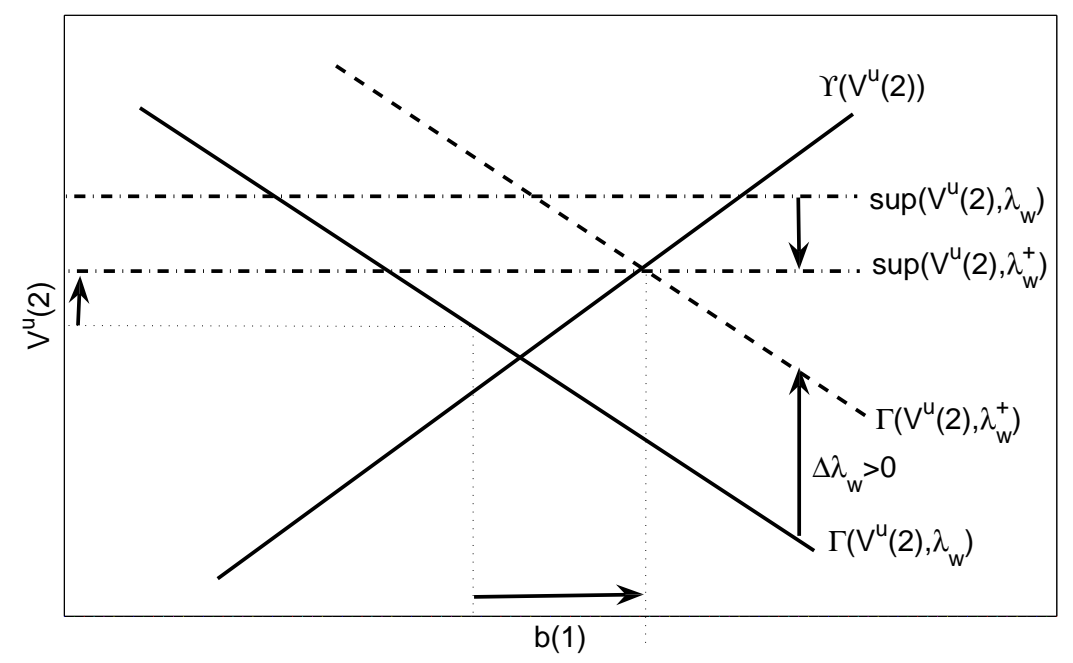

As $\lambda_{w}$ increases, the combination of equations (15) and (16) leads simultaneously to higher levels for $b(1)$ and $V^{u}(2)$, whereas the natural upper bound of unemployment value $\sup \left(V^{u}(2)\right)$ falls (Figure 5). There is a distance threshold $\widetilde{\lambda}_{w}$ such that the optimal level of $V^{u}(2)$ corresponds to $\sup \left(V^{u}(2)\right)$, implying that, for all horizons shorter than $\widetilde{\lambda}_{w}$, there is no interior solution (equation (16) no longer holds), i.e. the optimal contract is such that unemployment benefits are flat and search effort is zero. 


\section{The optimal pension tax with zero search}

When $a(t)=0, \forall t$, unemployment benefits and pension taxes are determined by the following two equations:

$$
\begin{aligned}
V^{u} & =\frac{u(\widetilde{b})}{1-\beta\left(1-\lambda_{w}\right)}+\frac{\lambda_{w} \beta}{1-\beta\left(1-\lambda_{w}\right)} V^{r}\left(\widetilde{\tau}^{r}\right) \\
V^{r}\left(\widetilde{\tau}^{r}\right) & =\frac{u\left(p-\widetilde{\tau}^{r}\right)}{1-\beta\left(1-\lambda_{r}\right)}
\end{aligned}
$$

These last two equations and equation (12) lead to:

$$
V^{u}=u(\widetilde{b})\left[\frac{1-\beta\left(1-\lambda_{w}-\lambda_{r}\right)}{\left[1-\beta\left(1-\lambda_{w}\right)\right]\left[1-\beta\left(1-\lambda_{r}\right)\right]}\right]
$$

On the other hand, we have the expression for promise-keeping $V$ :

$$
\begin{aligned}
V= & u(b)\left[\frac{1-\beta\left(1-\lambda_{w}-\lambda_{r}\right)}{\left[1-\beta\left(1-\lambda_{w}\right)\right]\left[1-\beta\left(1-\lambda_{r}\right)\right]}\right] \\
& +[u(p)-u(b)] \frac{\lambda_{w} \beta}{\left[1-\beta\left(1-\lambda_{w}\right)\right]\left[1-\beta\left(1-\lambda_{r}\right)\right]}
\end{aligned}
$$

As $V^{u}=V$, from equations (17) and (18), it can be deduced that $\widetilde{b}>b$ when $\lambda_{w}>0$ and that $\widetilde{b} \rightarrow b$ when $\lambda_{w} \rightarrow 0$.

\section{E The computational methodology}

The computational strategy draws on Sargent and Ljungqvist (2000), with an approximation of the $i$ th iterate $C_{i}\left(V^{u}\right)$ of the cost function $C\left(V^{u}\right)$ using Chebyshev polynomials. The numerical procedure consists of the following steps:

1. Choose a contract (wage or pension tax). Define a grid on the tax rate.

2. Choose a probability of retirement $\lambda_{w}$

3. Choose upper and lower bounds for $V^{u}$, so that $V$ and $V^{u}$ will be understood to reside in the interval $\left[\underline{V^{u}}, \overline{V^{u}}\right]$.

4. Choose a degree $n$ for the approximator, a Chebyshev polynomial, and a number $m$ $\succeq n+1$ of nodes or grid points.

5. Generate the $m$ zeros of the Chebyshev polynomial on the set $[1,-1]$.

6. By a change of scale, transform Chebyshev nodes to corresponding points $V^{u}$ in $\left[\underline{V^{u}}, \overline{V^{u}}\right]$. 
7. Choose initial values of the $n+1$ coefficients in the Chebyshev polynomial. Use these coefficients to define the function $C_{i}\left(V^{u}\right)$ for iteration number $i=0$.

8. Look at the optimal search effort choice (equation (1)). If equation (1) holds with equality, it determines the level of search effort $a$, otherwise, $a=0$.

9. Compute $\tilde{C}_{i}\left(V^{u}\right)$, the objective of the principal, as a function of $C_{i}\left(V^{u}\right)$, search effort, taxes, unemployment benefits as described in Section 2.2.

10. For each point $V^{u}$ and each tax rate, use a numerical minimization program to find $C_{i+1}\left(V^{u}\right)=\operatorname{Min} \tilde{C}_{i}\left(V^{u}\right)$.

11. Using these $m$ values of $C_{i+1}\left(V^{u}\right)$, compute new values of the coefficients in the Chebyshev polynomials with least squares.

12. Return to step 7, using the new values of the coefficients in the Chebyshev polynomials, and iterate to convergence.

For a contract and a retirement probability, the algorithm defines the sequence of unemployment benefits and tax rates. 
12-1. What drives Health Care Expenditure in France since 1950? A time-series study with structural breaks and non-linearity approaches

Thomas Barnay, Olivier Damette

12-2. How to account for changes in the size of Sports Leagues: The Iso Competitive Balance Curves

Jean-Pascal Gayant, Nicolas Le Pape

12-3. Hedonic model of segmentation with horizontal differentiated housing

Masha Maslianskaia-Pautrel

12-4. Stricter employment protection and firms' incentives to train: The case of French older workers

Pierre-Jean Messe, Bénédicte Rouland

12-5. Advantageous Semi-Collusion Revisited: A Note

Kai Zhao

12-6. Entry mode choice and target firm selection: private and collective incentive analysis

Kai Zhao 
11-1. The French "Earned Income Supplement" (RSA) and back-to-work incentives Denis Anne, Yannick L'Horty

11-2. The effect of place of residence on access to employment: a field experiment on qualified young job applicants in Ile-de-France

Yannick L'Horty, Emmanuel Duguet, Loïc du Parquet, Pascale Petit, Florent Sari

11-3. Why is there a faster return to work near the border?

Jonathan Bougard

11-4. Residential Discrimination and Ethnic Origin: An experimental assessment in the Paris suburbs

Emmanuel Duguet, Yannick L'Horty, Pascale Petit

11-5.The Fateful Triangle: Complementarities between product, process and organisational innovation in the UK and France

Gérard Ballot, Fathi Fakhfakh, Fabrice Galia, and Ammon Salter

11-6. How important is innovation? A Bayesian factor-augmented productivity model on panel data

Georges Bressona, Jean-Michel Etienne, Pierre Mohnen

11-7. Fiscal Shocks in a Two Sector Open Economy

Olivier Cardi, Romain Restout

11-8. Productivity, Capital and Labor in Labor-Managed and Conventional Firms

Fathi Fakhfakh, Virginie Pérotin, Mónica Gago

11-9. What is the Natural Weight of the Current Old ?

Damien Gaumont, Daniel Leonard

11-10. Routinization-Biased Technical Change, Globalization and Labor Market Polarization: Does Theory Fit the Facts?

Jaewon Jung, Jean Mercenier 
The CNRS Institute for Labor Studies and Public Policies (the TEPP Institute, FR $n^{\circ} 3435$ CNRS) gathers together research centres specializing in economics and sociology:

- l'Equipe de Recherche sur les Marchés, l'Emploi et la Simulation (Research Team on Markets, Employment and Simulation), ERMES, University of Paris II PanthéonAssas

- the Centre d'Etudes des Politiques Economiques de l'université d'Evry (Research Centre focused on the analysis of economic policy and its foundations and implications), EPEE, University of Evry Val d'Essonne

- the Centre Pierre Naville (Research on Work and Urban Policies), CPN, University of Evry Val d'Essonne

- l'Equipe de Recherche sur l'Utilisation des Données Temporelles en Economie (Research Team on Use of Time Data in Economics), ERUDITE, University of ParisEst Créteil and University of Paris-Est Marne-la-Vallée

- the Groupe d'Analyse des Itinéraires et des Niveaux Salariaux (The Group on Analysis of Wage Levels and Trajectories), GAINS, University of the Maine

The TEPP Institute brings together 147 researchers and research professors and $100 \mathrm{PhD}$ students who study changes in work and employment in relation to the choices made by firms and analyse public policies using new evaluation methods. 